\title{
A Novel Method to Fabricate CNT/Mg-6Zn Composites with High Strengthening Efficiency
}

\author{
Hailong Shi $\cdot$ Xiaojun Wang $\cdot$ Chendong Li $\cdot$ Xiaoshi Hu $\cdot$ Chao Ding $\cdot$ Kun Wu $\cdot$ Yudong Huang
}

Received: 9 May 2014/Revised: 21 August 2014/Published online: 1 October 2014

(C) The Chinese Society for Metals and Springer-Verlag Berlin Heidelberg 2014

\begin{abstract}
A novel method was developed to fabricate carbon nanotubes (CNTs)-reinforced Mg matrix composites. The method consists of two steps: CNTs pre-dispersion by ball-milling and the ultrasonic melt processing. Mechanical ballmilling effectively pre-dispersed CNTs on Zn flakes with suitable rotational speed and ball-milling time. Serious CNT entanglements were dispersed by the ball-milling. However, ball-milling for a long time at high speed would damage the morphology of CNTs. The ultrasonic overcame the poor wettability between Mg melt and CNTs and then dispersed predispersed CNTs in the Mg melt. CNTs were distributed well in the composites and maintained integrated structure. CNTs significantly improved the mechanical properties of the matrix. The strengthening efficiency reached to 37.1 , which proves the superiority of this novel method. Besides grain refinement, load transfer may make a great contribution to the improvement of the strength for the composites.
\end{abstract}

KEY WORDS: Pre-dispersion; Carbon nanotubes; Magnesium matrix composites; Mechanical properties; Ultrasonic vibration

\section{Introduction}

CNTs exhibit extremely high elastic modulus and strength as well as good thermal and electrical properties, and it was found at the first time in 1991 by Lijima [1]. CNTs are being employed as the reinforcement in metal matrix and polymer matrix composites. At present, a great success has already been achieved in polymer matrix composites reinforced by CNTs [2]. There are also a lot of researches on CNTs-reinforced metal matrix composites, especially

Available online at http://link.springer.com/journal/40195

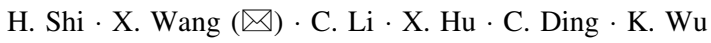
School of Materials Science and Engineering, Harbin Institute of Technology, Harbin 150001, China

e-mail: xjwang@hit.edu.cn

X. Wang $\cdot$ Y. Huang

School of Chemical Engineering and Technology, Harbin

Institute of Technology, Harbin 150001, China
$\mathrm{Al}$ and $\mathrm{Cu}$ matrix composites [3, 4]. However, further work needs to be carried out on CNTs-reinforced metal matrix composites, because CNTs are much more difficult to disperse in metal matrix than in polymer matrix [5].

$\mathrm{Mg}$ and its alloys are regarded as a potential matrix for CNTs because of their chemical compatibility with CNTs. Generally speaking, CNTs are employed to increase the strength, stiffness, ductility, and even the electrical conductivity of $\mathrm{Mg}$ matrix. To achieve the above purposes, CNTs should obtain a uniform dispersion in the Mg matrix. So far, the uniform dispersion of CNTs is not well realized in $\mathrm{Mg}$ matrix, although many methods have been successfully developed to disperse CNTs in $\mathrm{Al}, \mathrm{Ti}$, and $\mathrm{Cu}$ matrix, such as the modified powder metallurgy [6], friction stir processing, [7] and molecular-level mixing [2]. However, those methods are not very suitable to fabricate $\mathrm{CNT} / \mathrm{Mg}$ composites, since $\mathrm{Mg}$ is chemically active. For example, it is very dangerous to directly ball-mill $\mathrm{Mg}$ with CNTs, because Mg powders are flammable and explosive. Thus, it is very necessary to develop a novel method for 
$\mathrm{CNT} / \mathrm{Mg}$ composite to realize the uniform dispersion of CNTs.

The superiority of $\mathrm{Mg}$ is good compatibility between CNTs and Mg melt. Given this, the melt processing can be a good method to fabricate CNT/Mg. Furthermore, the melt processing has achieved great success in CNTs-reinforced polymer matrix composites. However, it is very difficult to disperse CNTs directly in metallic melts due to serious CNTs entanglement and poor wettability besides chemical compatibility [5]. For CNTs entanglement caused by the strong Van der Waals' force, the pre-dispersion of CNTs is necessary before adding CNTs to melts. At present, two types of dispersion methods are studied by researchers: chemical methods and ball-milling. The chemical methods are effective in dispersing CNT clusters, but they are too complicated and very inefficient in production. In comparison, ballmilling process is very simple and efficient in production [810]. In addition, the ball-milling process can be easily controlled by adjusting the rotational speed, milling time, and ball-to-powder weight ratio. Thus, the mechanical ballmilling is a good choice for CNTs pre-dispersion.

After CNTs were added to Mg melt, the CNTs cannot be well dispersed by simple mechanical stir due to the poor wettability between $\mathrm{Mg}$ and CNTs. However, the highenergy ultrasonic can effectively disperse the clusters of nano-reinforcements in metal melts because of transient ultra-high temperatures and ultra-high heating and cooling rates caused by the ultrasonic cavitation [11]. The highenergy ultrasonic can not only disperse nano-reinforcements, but also significantly improve the wettability between reinforcements and $\mathrm{Mg}$ [12]. Thus, the highenergy ultrasonic may effectively disperse pre-dispersed CNTs in Mg. However, the related researches on CNTsreinforced metal matrix composites are very limited.

In this work, a novel melt processing by combining the ball-milling pre-dispersion and ultrasonic treatment was developed to disperse the CNTs into the Mg melt to produce CNT/Mg composites. The CNTs microstructure and mechanical properties of the resultant composites were analyzed and evaluated.

\section{Experimental}

In this study, CNT/Mg composites were fabricated through two steps. First, $\mathrm{Zn}$ powders were selected as the ballmilling carrier to pre-disperse CNTs, because Zn powders are safe to ball-milling and chemically compatible with CNTs in Mg melts. Zn powders can segment the dispersed CNTs and prohibit the re-entanglement of CNTs after ballmilling. CNTs and Zn powders were ball-milled to predisperse CNTs on $\mathrm{Zn}$ flakes, and the mixture powders were compressed into a block to obtain $\mathrm{CNT} / \mathrm{Zn}$ precursor.

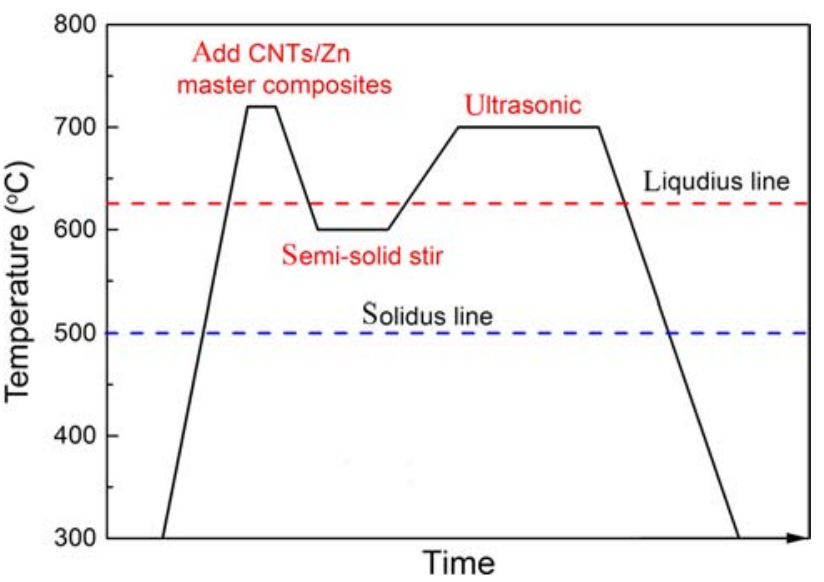

Fig. 1 Temperature-time flow chart of the composites fabricating

Then, the CNT/Zn precursor was added into the pure $\mathrm{Mg}$ melt and processed by mechanical stirring. Finally, as-cast $\mathrm{CNT} / \mathrm{Mg}$ composites were obtained after high-energy ultrasonic was introduced into the melt. The processing schematic illustration is shown in Fig. 1.

Multiwalled CNTs (MWCNTs) (Chengdu Organic Chemistry Co. Ltd., China. Diameter: 40-60 nm; length: $<2 \mu \mathrm{m}$ ), which were synthesized using chemical vapor deposition (CVD), pure Zn powders (size of $\sim 70 \mu \mathrm{m}$ ), and pure $\mathrm{Mg}$ ingot were used as the raw materials. The ballmilling experiments were carried out in a planetary ballmilling apparatus. The mixtures of CNTs and pure $\mathrm{Zn}$ powders were put into the stainless steel container with alcohol as the medium. During the ball-milling step, the effect of ball-milling speed and time on the dispersion of CNTs was studied. The mixture powders were ball-milled at 200,300, and $400 \mathrm{r} / \mathrm{min}$ for $1,4,8$, and $10 \mathrm{~h}$. After drying, the mixture powders were cold-pressed with $\mathrm{Mg}$ chips under $\sim 100 \mathrm{MPa}$ pressure at room temperature, then were hot pressed at $190{ }^{\circ} \mathrm{C}$ under $150 \mathrm{MPa}$.

For the melting processing, a pure $\mathrm{Mg}$ ingot was melted at $675{ }^{\circ} \mathrm{C}$ in $\mathrm{CO}_{2}+\mathrm{SF}_{6}$ protective atmosphere firstly. Next, the CNT/Zn precursor was added into the Mg melt. Then, the melt containing CNTs was stirred in semi-solid condition. The stir process was conducted at $580{ }^{\circ} \mathrm{C}$ for $10 \mathrm{~min}$ with the stirring speeds of $800-1400 \mathrm{r} / \mathrm{min}$. After semi-solid stir, the melt was rapidly reheated to $690{ }^{\circ} \mathrm{C}$, and then a $450 \mathrm{~W}$ ultrasonic probe was introduced into the melt for $20 \mathrm{~min}$. Then, the melt was elevated to a pouring temperature of $720{ }^{\circ} \mathrm{C}$ and cast into a preheated steel mold $\left(375^{\circ} \mathrm{C}\right)$. It should be noted that ultrasonic vibration was not used during the solidification process. For comparison, an $\mathrm{Mg}-6 \mathrm{Zn}$ alloy ingot without semi-solid stir and ultrasonic vibration was also cast under the same conditions.

Optical microscopy (OM), scanning electron microscopy (SEM) (Quanta 200FEG), and transmission electron microscopy (TEM) (Tecnai F30) were used to observe pre- 

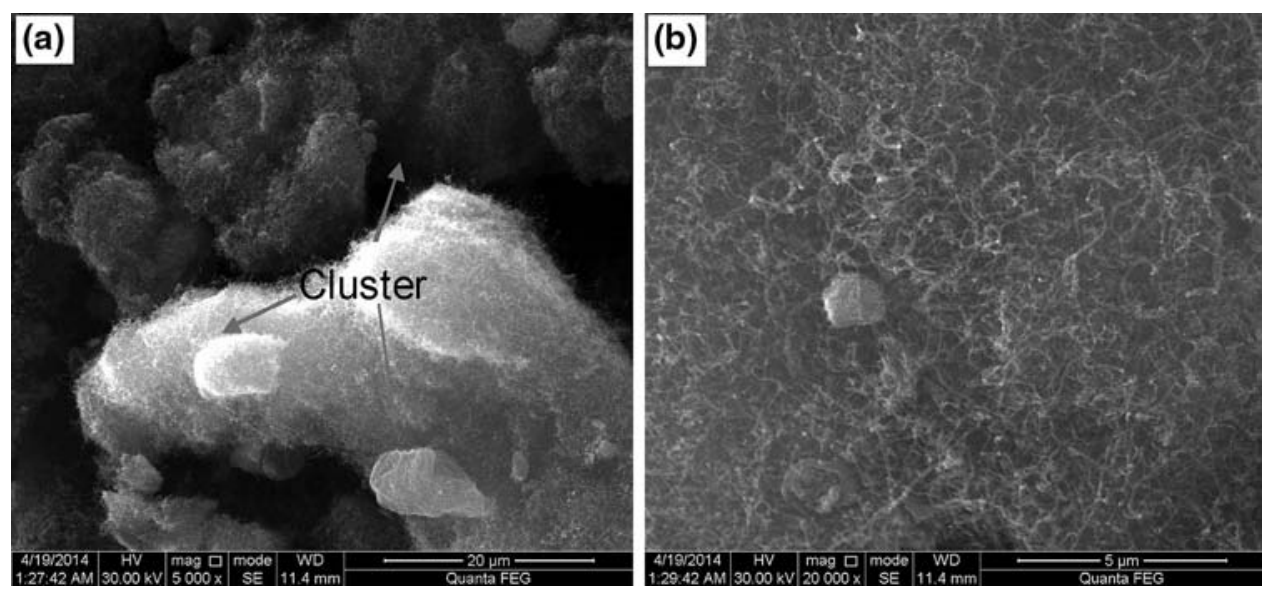

Fig. 2 Morphology of the raw CNTs: a low-magnification image; b high-magnification image
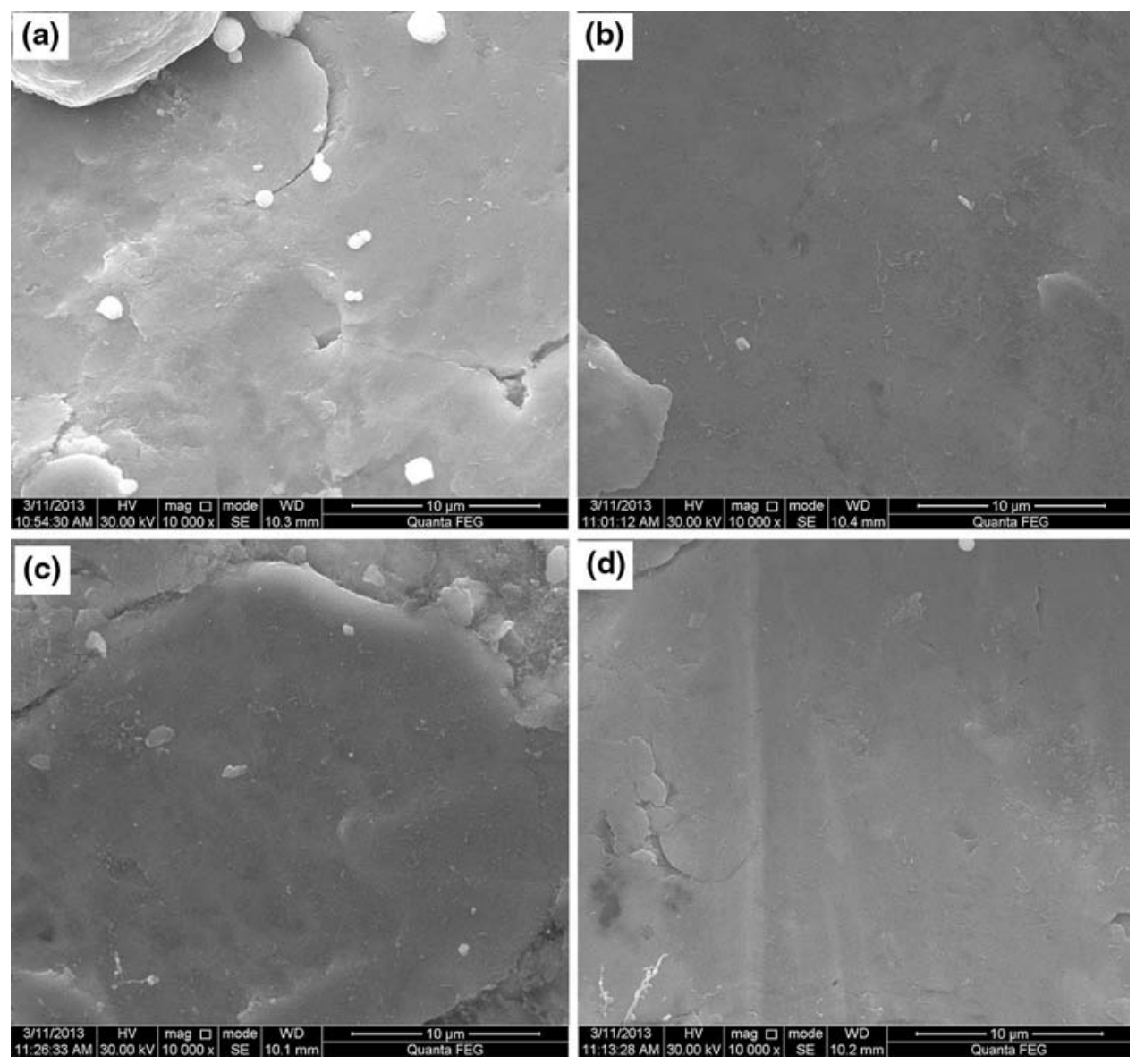

Fig. 3 SEM images showing the CNT distribution on Zn flakes after ball-milling at $200 \mathrm{r} / \mathrm{min}$ for $1 \mathrm{~h} \mathbf{a}, 4 \mathrm{~h} \mathrm{~b}, 8 \mathrm{~h} \mathrm{c}, 10 \mathrm{~h} \mathrm{~d}$

dispersed CNT/Zn powders and the microstructure of the composite. Grain sizes of $\mathrm{Mg}-6 \mathrm{Zn}$ alloy and CNT/Mg composites were measured by two-phase linear analysis. The specimens for microstructure analysis were mechanically polished and etched by picric acid $(5 \mathrm{~mL}$ acetic acid $+5.5 \mathrm{~g}$ picric acid $+100 \mathrm{~mL} \quad \mathrm{H}_{2} \mathrm{O}+90 \mathrm{~mL}$ ethanol). Specimens for TEM observation were firstly prepared by grinding-polishing the sample to produce a foil of $50 \mu \mathrm{m}$ thickness followed by punching 3-mm-diameter disks and then thinned by ion beam.

Five dog-bone shape samples of as-cast alloy and composites (thickness: 1.6-1.8 mm; length: $25 \mathrm{~mm}$; width: 

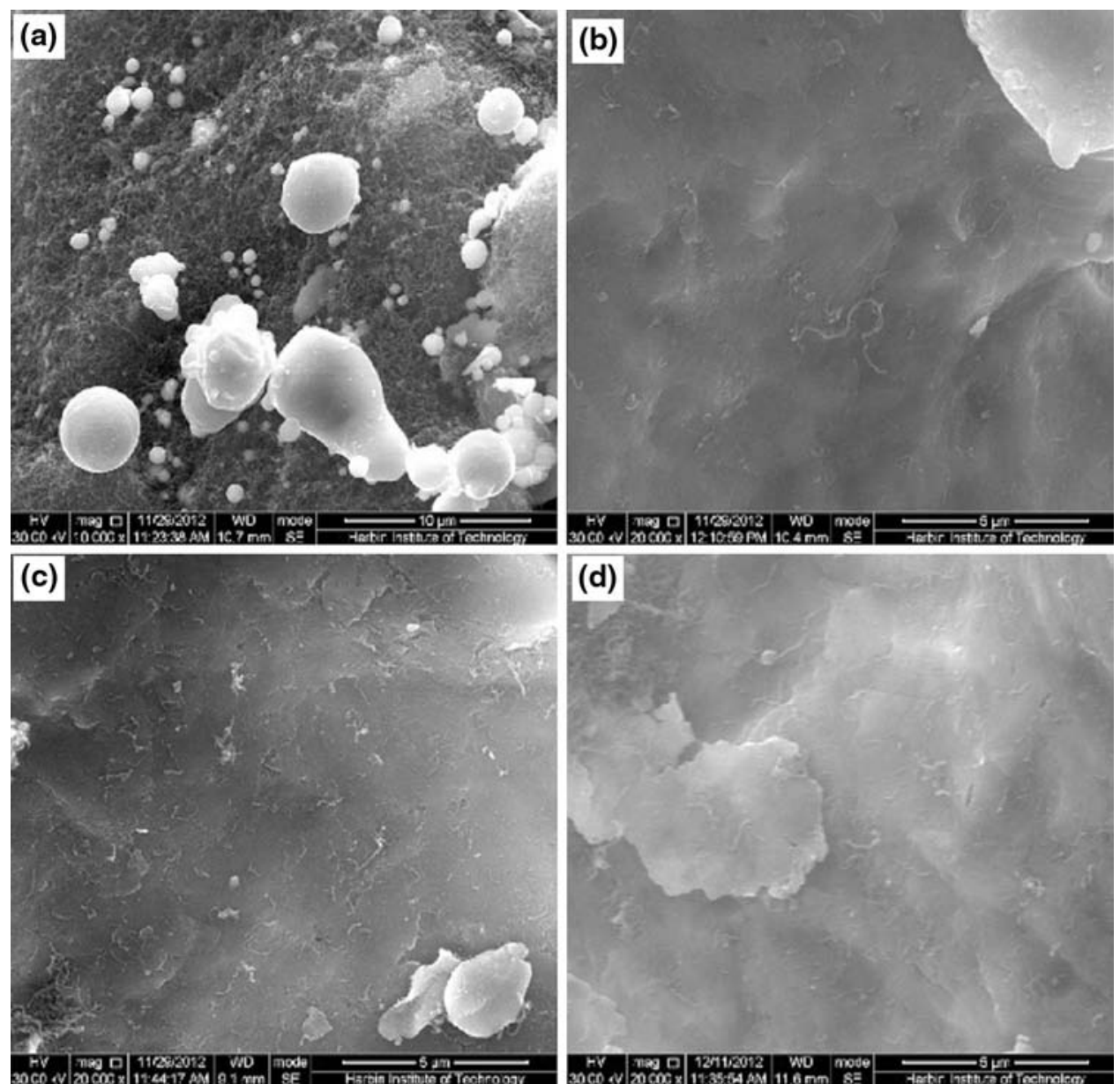

Fig. 4 SEM images showing the CNTs distribution on Zn flakes after ball-milling at $300 \mathrm{r} / \mathrm{min}$ for $1 \mathrm{~h} \mathrm{a}, 4 \mathrm{~h} \mathrm{~b}, 8 \mathrm{~h} \mathrm{c}, 10 \mathrm{~h} \mathrm{~d}$

$5.5-6.5 \mathrm{~mm}$ ) were tested by room-temperature tensile tests to investigate the mechanical properties. The tensile tests were in accordance with ASTM: E8/E8 M-13a standards. Yield strength (YS), ultimate tensile strength (UTS), elastic modulus $(E)$, and elongation $(\delta)$ were obtained based on the average of $3-5$ tests.

\section{Results and Discussion}

\subsection{CNTs Pre-disperse}

As shown in Fig. 2a, the raw CNTs seriously tangled to large clusters. It would be extremely difficult to disperse these CNTs in Mg melt if they were directly added into $\mathrm{Mg}$ melt without pre-dispersion. Therefore, pre-dispersion of CNTs is indispensable in order to obtain uniform CNT distribution in the composites. Figures 3, 4, and 5 show the morphology of the pre-dispersed CNTs at different ball-milling parameters (different rotational speed and time). It is clear that almost no CNTs were well dispersed on $\mathrm{Zn}$ flakes at $200 \mathrm{r} / \mathrm{min}$ (Fig. 3). This indicates that the ball-milling at $200 \mathrm{r} / \mathrm{min}$ could not effectively break up the serious entanglements of CNTs and disperse CNTs on the $\mathrm{Zn}$ flakes. The dispersity of CNTs was improved when the ball-milling speeds raised to $300 \mathrm{r} / \mathrm{min}$. However, only a small number of individual CNTs were observed on the $\mathrm{Zn}$ flakes, even after $8 \mathrm{~h}$ ball-milling (Fig. 4). All these indicate that ball-milling at lower speeds could not effectively break up the serious entanglements of CNTs.

As the welding speed increased to $400 \mathrm{r} / \mathrm{min}$, a mass of individual CNTs appeared on Zn flakes when ball-milled for $4 \mathrm{~h}$, which means the serious CNTs entanglements were broken up and CNTs were dispersed, although there still existed some very tiny clusters of CNTs at $4 \mathrm{~h}$, as shown in Fig. 5b. It is clear that ball-milling is an effective predispersion method. During ball-milling process, the collision and friction between balls and CNTs would help to break the entanglement of raw CNTs into pieces. As the ball-milling time increased to 8 and $10 \mathrm{~h}$, the length of CNTs was evidently cut off, although tiny clusters of CNTs were further reduced. This indicates that the structure of CNTs was damaged. 

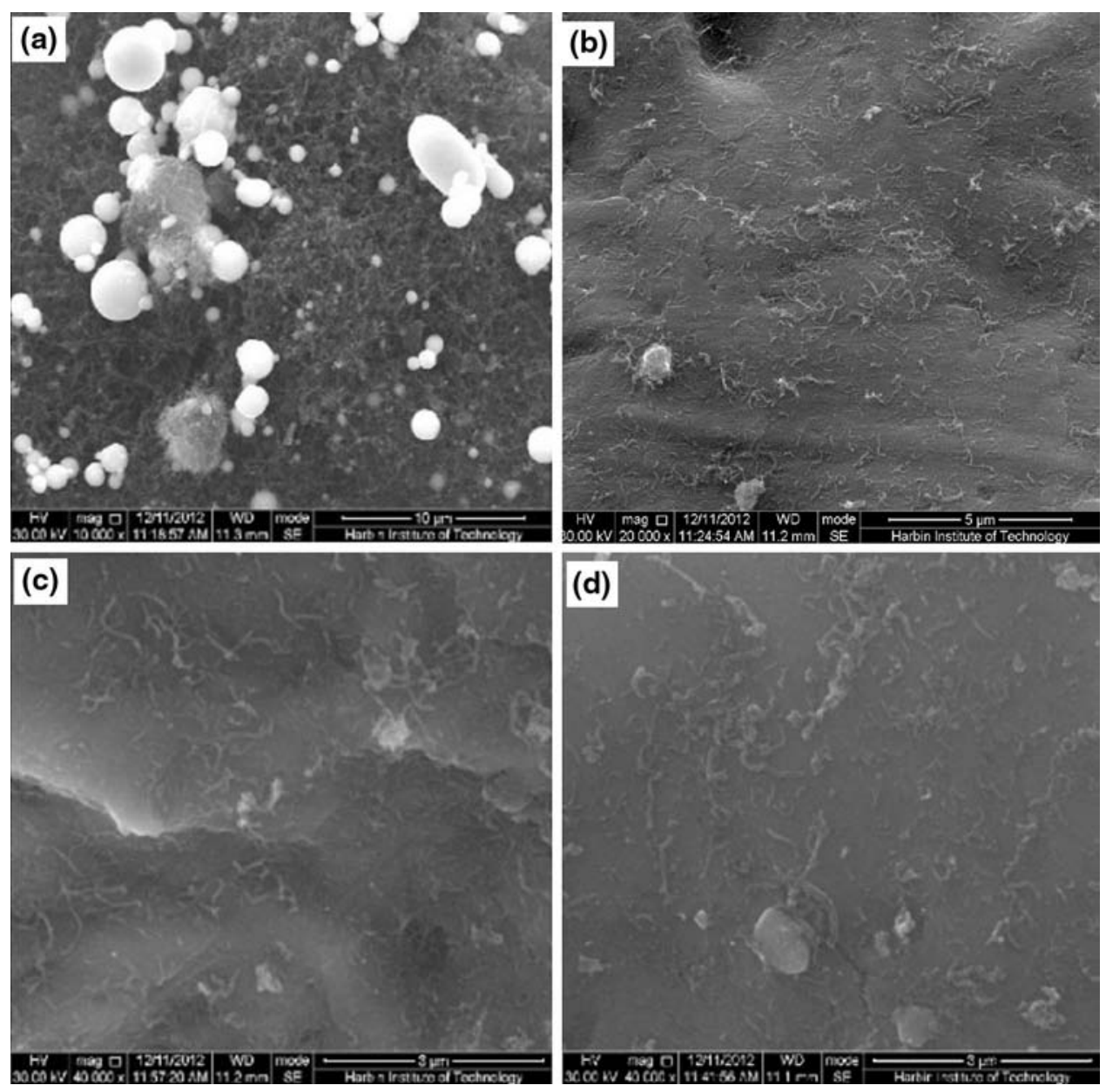

Fig. 5 SEM images showing the CNTs distribution on Zn flakes after ball-milling at $400 \mathrm{r} / \mathrm{min}$ for $1 \mathrm{~h} \mathrm{a}, 4 \mathrm{~h} \mathrm{~b}, 8 \mathrm{~h} \mathbf{c}, 10 \mathrm{~h} \mathrm{~d}$

It should be noted that the pre-dispersion is aimed to break the serious CNTs entanglements to pieces, and it is necessary to keep the integrity of CNTs. Thus, through a comprehensive comparison of the dispersion effect of CNTs at different experiment conditions, ball-milling for $5 \mathrm{~h}$ at $400 \mathrm{r} / \mathrm{min}$ was finally chosen to pre-disperse CNTs on $\mathrm{Zn}$ flakes in our experiment.

It is noted that it is necessary to prevent the CNTs from being oxygenated during the powder-adding process. Thus, the mixed powders were compressed into a cylinder-shaped block $(\Phi 60 \mathrm{~mm} \times 25 \mathrm{~mm})$ as shown in Fig. 6. In this way, $\mathrm{CNT} / \mathrm{Zn}$ precursors with a uniform dispersion of CNTs were fabricated. Inside the CNT/Zn precursors, CNTs were segregated by $\mathrm{Zn}$ flakes which prevent them from reuniting again.

\subsection{Melt Processing}

As shown in Fig. 7, the clusters of CNTs were not observed in the as-cast composites, and many single CNTs were observed. The tiny clusters after dispersion were also found. All these indicate that the ultrasonic succeeded in overcoming the poor wettability between $\mathrm{Mg}$ melt and CNTs and then dispersing pre-dispersed CNTs in Mg melt. The melt processing consists of two stages: mechanical stir in the semi-solid condition and ultrasonic treatment in the liquid condition. After the CNT/Zn precursors were added into the pure $\mathrm{Mg}$ melt, mechanical stirring was conducted in its semi-solid condition. The aim of the mechanical stirring is preparatory dispersion for ultrasonic. Reinforcements can be more effectively dispersed in the semisolid condition than in the liquid condition because of the friction and impact of solidified $\mathrm{Mg}$ [13]. In addition, CNTs are not easy to be oxidized due to the lower temperatures in the semi-solid condition. It should be noted that mechanical stirring in the semi-solid condition could not disperse CNTs clusters, so there still existed some tiny clusters of CNTs. However, CNTs achieved a uniform dispersion in a macroscopic scale after mechanical stirring. This can be considered to be preparatory dispersion for ultrasonic process.

To further disperse CNTs in the composites, highenergy ultrasonic was then introduced into the melt. During 


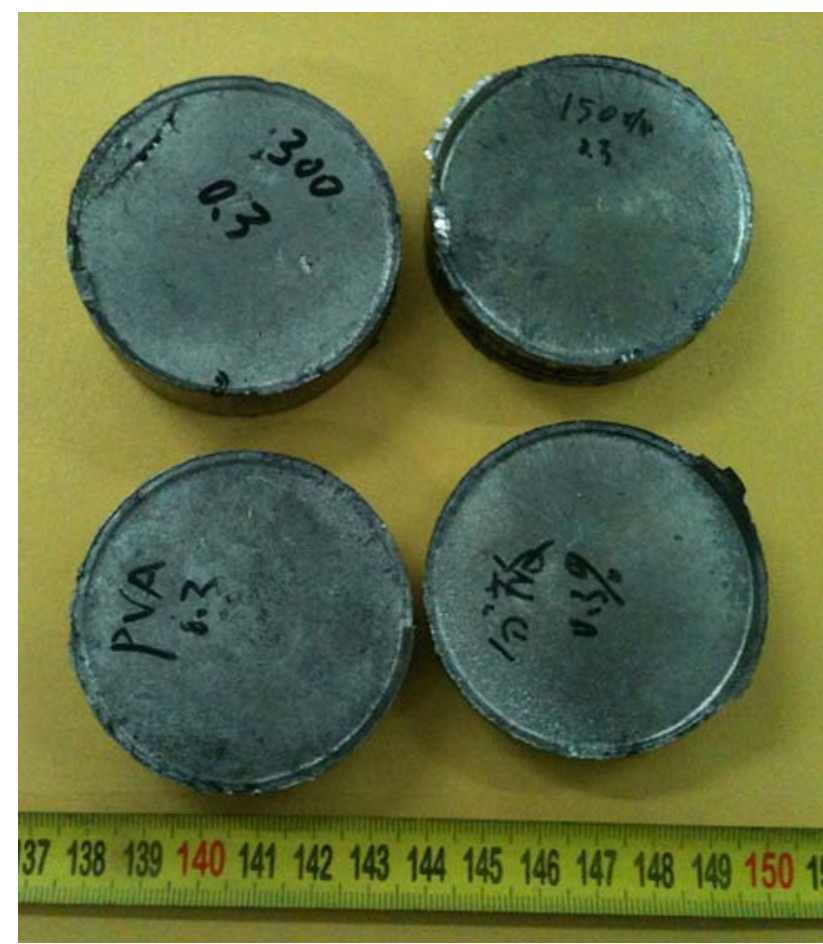

Fig. 6 Photographs of CNT/Zn precursor compacts

the ultrasonic treatment, periodical ultrasonic generated by the ultrasonic horn brought the acoustic cavitation effect into the melt which produced some vacuolations inside the melt [14]. These vacuolations and other tiny pores (such as tiny pores in small clusters of CNTs) grew continually under the excitation of the ultrasonic wave until they collapse. The collapse of these vacuolations will release enormous energy and a lot of heat and even produced instantaneous blast wave within a small volume. The pores in the composites are defects which would prominently harm the mechanical properties of the composites. Under effect of the ultrasonic cavitation, some of these pores can be filled with the matrix melt due to the collapse of some vacuolations outside the clusters, and the others broke up as the initial vacuolations. Therefore, most of the CNTs clusters were eliminated after mechanical stir and ultrasonic vibration process. A uniform dispersion of CNTs was achieved in the as-cast nanocomposites, as shown in Fig. 7.

Figure 8 shows TEM image of the composites. The multilayered structure of the nanotube can be observed clearly. No obvious microstructure damage was found on CNTs. All these means that the whole fabrication process can maintain integrated morphological structure. Besides, as we can see that the CNT-matrix interface is free of pore. This indicates that good interface bonding between CNTs and matrix was formed. This ensures that the load can be effectively transferred to CNTs when loading. As a result, the reinforcing potentiation of CNTs can be fully achieved. According to the above, the CNTs can be well dispersed in $\mathrm{Mg}-\mathrm{Zn}$ matrix through pre-dispersion and the ultrasonic melt process. Thus, a novel method was developed to fabricate CNT/Mg composites.

It should be noted that CNTs were dispersed along the grain boundary, as shown in Fig. 7. This was caused by the "push" effect of solidification front [13, 15]. During the solidification of the composites, most reinforcements were pushed to the solidification front when primary magnesium grains grew. As a result, CNTs were pushed to the intergranular regions during the impingement with other growing grains [13]. Thus, most CNTs were finally distributed along the grain boundaries. In addition, most second phases of the matrix were also located in the grain boundaries. Therefore, CNTs and second phases interacted in the grain boundaries. Some second phases wrapped CNTs, as shown in Fig. 7b.
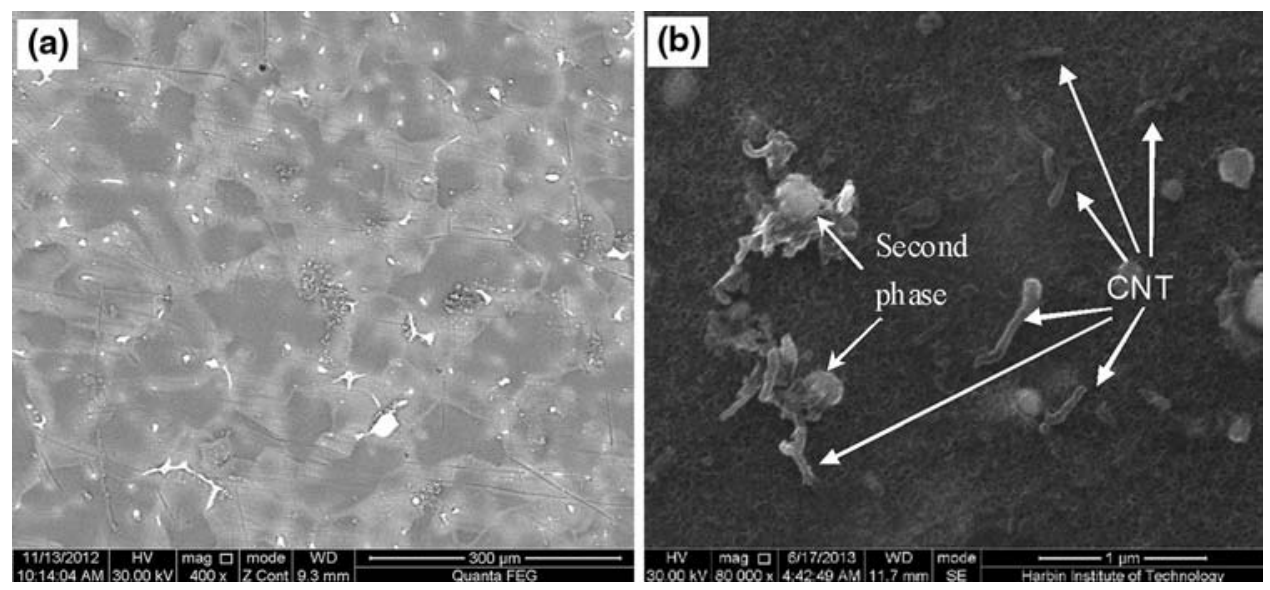

Fig. 7 SEM images of as-cast CNT/Mg-6Zn composite: a low-magnification image; b high-magnification image 

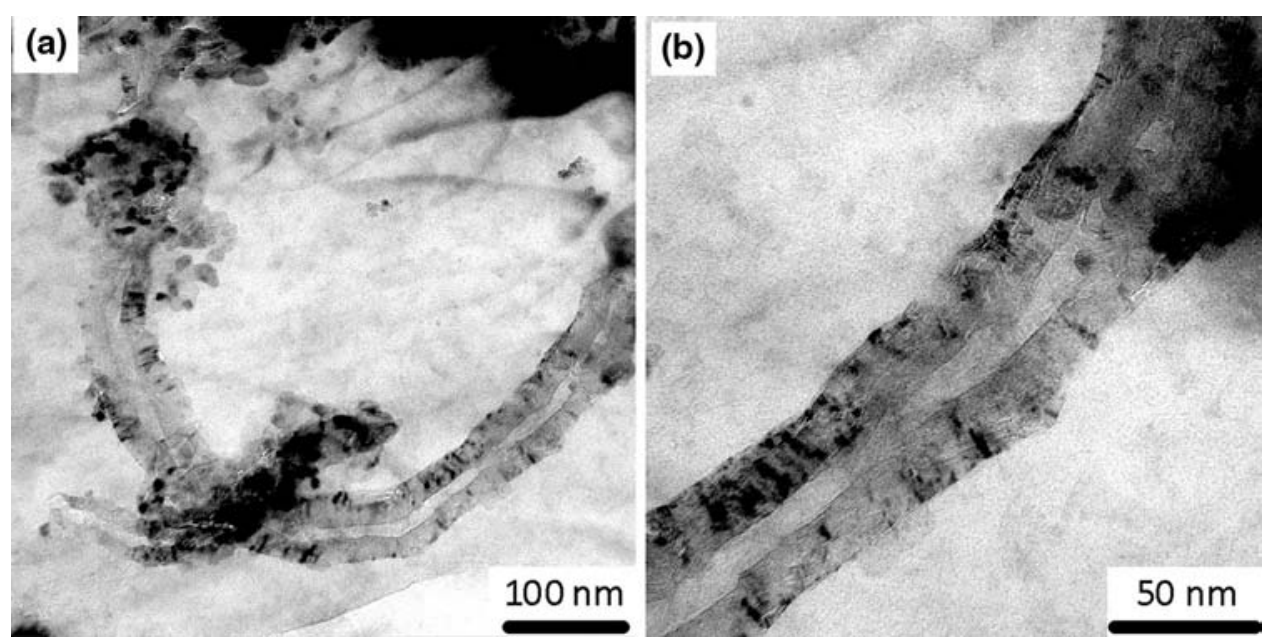

Fig. 8 TEM images of CNT/Mg-6Zn composite: a low-magnification image; b high-magnification image

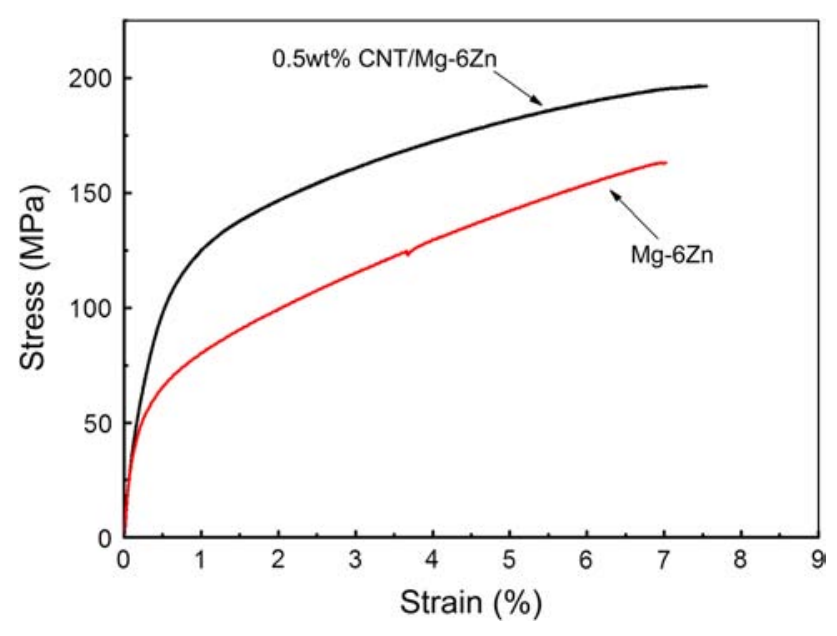

Fig. 9 Typical stress-strain curves of as-cast Mg alloy and CNT/ $\mathrm{Mg}-6 \mathrm{Zn}$ composite

\subsection{Mechanical Properties}

Figure 9 is the typical stress-strain curves of the alloy and the CNT/Mg-6Zn composites. It can be seen clearly that the addition of $0.5 \mathrm{wt} \%$ CNTs significantly enhanced the mechanical properties of $\mathrm{Mg}-6 \mathrm{Zn}$ composites, the YS, UTS, and elongation reached 92, $192 \mathrm{MPa}$, and 7.6\%, increasing by $64.3 \%, 24.8 \%$, and $7.0 \%$, respectively, as compared to those of $\mathrm{Mg}-6 \mathrm{Zn}$ alloy. The strengthening efficiency $(R)$ is usually used to evaluate the effect of CNT addition on the strength improvement of composites. $R$ is calculated by [16].

$R=\frac{\sigma_{\mathrm{c}}-\sigma_{\mathrm{m}}}{f_{\mathrm{v}} \sigma_{\mathrm{m}}}$,

where $\sigma_{\mathrm{c}}$ is the UTS of a given composite, $\sigma_{\mathrm{m}}$ is the UTS of the matrix, and $f_{v}$ is the volume fraction of CNTs. The $R$ values reached 37.1 in the present study. Generally, the
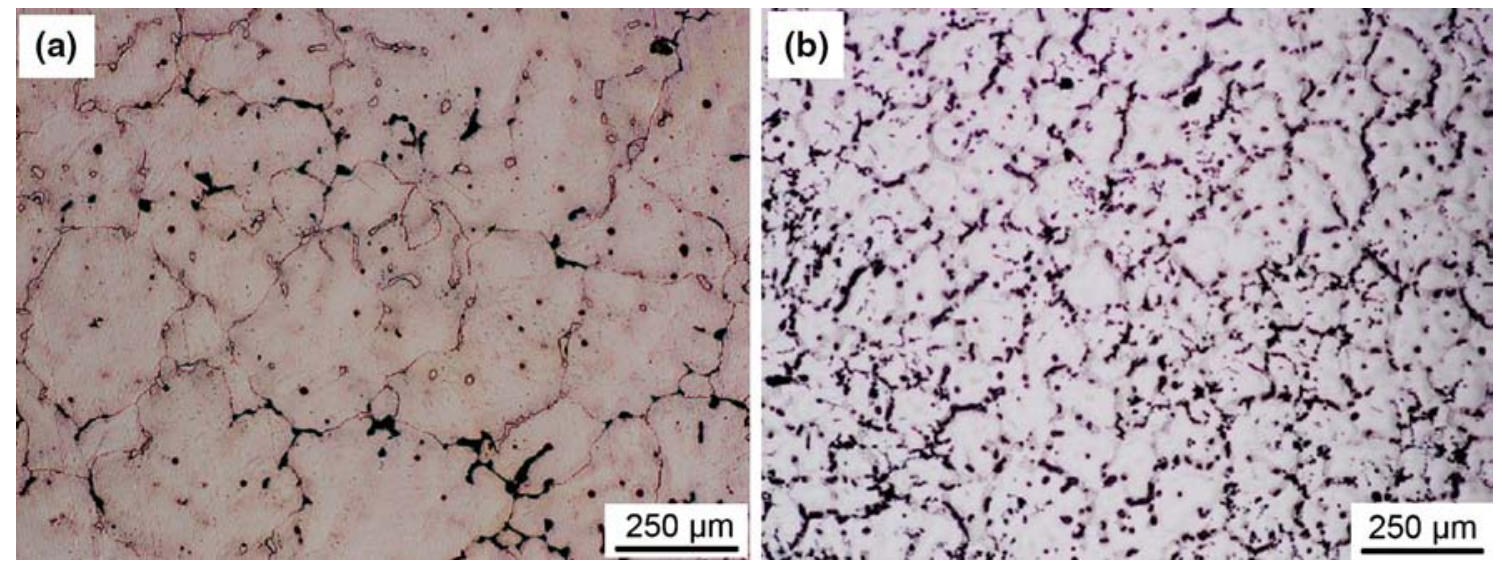

Fig. 10 Optical images of as-cast $\mathrm{Mg}-6 \mathrm{Zn}$ alloy a $\mathrm{CNT} / \mathrm{Mg}-6 \mathrm{Zn}$ composite b 

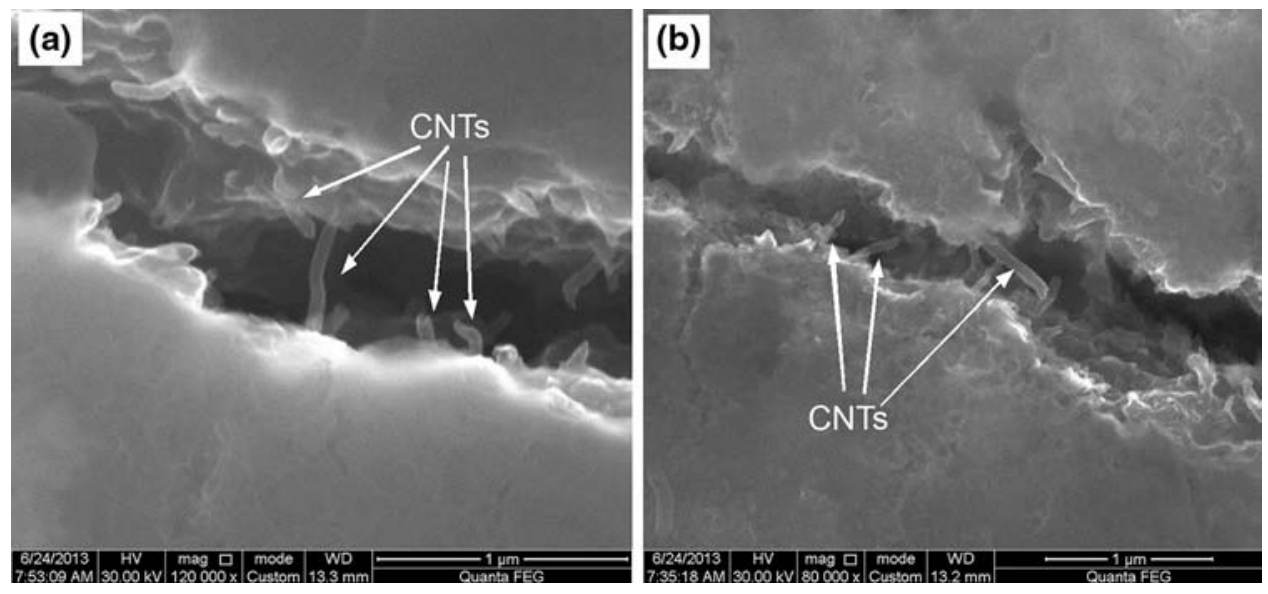

Fig. 11 SEM images of the fracture surfaces of CNT/Mg-6Zn composite (a) high magnification. (b) lower magnification

$R$ for CNT/Al composite ranges from 20 to 30 [15]. Thus, this $R$ value is very high in this study, which is attributed to uniform CNT dispersion, good integrity of CNTs, and good interface bonding in the composite [17]. This also proves the superiority of this novel method.

As shown in Fig. 10, the grain size of $0.5 \mathrm{wt} \% \mathrm{CNT} / \mathrm{Mg}-$ $6 \mathrm{Zn}(\sim 90 \mu \mathrm{m})$ was much smaller than that of the as-cast Mg-6Zn alloy $(\sim 200 \mu \mathrm{m})$. According to the classic HallPetch equation, the YS increase due to grain refinement is only about 4.6 MPa. In this study, the YS increase was $36 \mathrm{MPa}$. Thus, the grain refinement is only one of the reasons resulting in the enhancement in YS of the composite. Besides the grain refinement, there are other three possible strengthening mechanisms for CNT-reinforced MMCs: (1) an increase in dislocation density caused by thermal mismatch between a given composite matrix and CNTs; (2) Orowan mechanism; and (3) load transfer effect [16]. In the CNT/Mg composites, CNTs were mainly distributed along the grain boundaries with the second phases. Thus, the orowan mechanism may not play a role. Load transfer and an increase in dislocation density caused by thermal mismatch may make a great contribution to the YS increase. As shown in Fig. 11, there were many individual CNTs stretched out from the precipice of the microcracks, indicating that the load transfer was operative. When the composites were loaded, the matrix would fracture firstly, while the ultra-high strength of CNTs makes them undertake higher loading. As the load increased, to the strength of the CNT-Matrix interface, the CNTs were pulled out from the matrix and the microcrack was further extended [18]. In this way, CNTs delayed the fracture of the composites and make the composites bear higher load (Fig. 10).

For the composites reinforced by short fiber or whisker, the load transfer effect depends on the length of the reinforcements. For the present study, the critical length $\left(l_{\mathrm{c}}\right)$ can be defined as $[6,19]$ : $l_{\mathrm{c}}=\sigma_{\mathrm{f}} \cdot d_{\mathrm{f}} / \sigma_{\mathrm{m}}$,

where $\sigma_{\mathrm{m}}$ is the strength of the matrix, $\sigma_{\mathrm{f}}$ is the strength of the fiber, and $d_{\mathrm{f}}$ is the average diameter of the fibers (about $50 \mathrm{~nm}$ ). The calculated $l_{\mathrm{c}}$ for the CNT/Mg-6Zn composite is about $9.5 \mu \mathrm{m}$. The CNT length used in this study was about $2 \mu \mathrm{m}$. For nanotube lengths $l<l_{\mathrm{c}}$, the fracture strength of the composites can be estimated through the Kelly-Tyson formula [20]:

$\sigma_{\mathrm{c}}=V_{\mathrm{CNT}} \cdot \sigma_{\mathrm{CNT}}\left(l /\left(2 l_{\mathrm{c}}\right)\right)+V_{\mathrm{m}} \cdot \sigma_{\mathrm{m}}$,

where $\sigma_{\mathrm{c}}$ and $\sigma_{\mathrm{m}}$ are the strengths of the composites and the matrix, respectively, $\sigma_{\mathrm{CNT}}$ is the strength of the CNT (about $30 \mathrm{GPa}$ ), $V_{\mathrm{CNT}}$ and $V_{\mathrm{m}}$ are the volume fraction of the CNTs and the matrix, respectively, and $l_{\mathrm{c}}$ is the critical length, which is calculated by Eq. (2). Through calculation, the strength increase due to load transfer was about 20.1 MPa. In our experiment, the strength of the matrix alloy increased by $39 \mathrm{MPa}$. It is clear that load transfer did make a great contribution to the strength increase.

\section{Conclusions}

(1) Mechanical ball-milling can effectively pre-disperse CNTs on Zn flakes with suitable rotational speed and ball-milling time. Serious CNTs entanglements were dispersed by the ball-milling. However, ball-milling for a long time at high speed would damage the integrity of CNTs.

(2) The ultrasonic can overcome the poor wettability between $\mathrm{Mg}$ melt and CNTs and then disperse predispersed CNTs in Mg melt. CNTs were distributed well in the composites and maintained integrated morphological structure. 
(3) CNTs significantly improved the mechanical properties of the matrix. The strengthening efficiency reached 37.1, which is attributed to uniform CNT dispersion, good integrity of CNTs, and good interface bonding in the composites. This also proves the superiority of this novel method. Besides grain refinement, load transfer may make a great contribution to the improvement of the strength for the composites.

Acknowledgements This work was financially supported by the National Natural Science Foundation of China (No. 51101043 and 51471059), Key Project of Science and Technology Department of Heilongjiang Province of China (No. GC12A109), and the China Postdoctoral Science Foundation (No. 2013M531035 and 2014T70328).

\section{References}

[1] S. Lijima, Nature 354, 56 (1991)

[2] S.I. Cha, K.T. Kim, S.N. Arshad, C.B. Mo, S.H. Hong, Adv. Mater. 17, 1377 (2005)

[3] S.C. Tjong, Mater. Sci. Eng. R 74, 281 (2013)

[4] X.X. Zhang, L. Yang, C.F. Deng, D.Z. Wang, Trans. Nonferrous Met. Soc. China 16, s1465 (2006)

[5] S.R. Bakshi, D. Lahiri, A. Agarwal, Int. Mater. Rev. 55, 41 (2010)
[6] L. Jiang, Z.Q. Li, G.L. Fan, L.L. Cao, D. Zhang, Carbon 50, 1993 (2012)

[7] Z.Y. Liu, B.L. Xiao, W.G. Wang, Z.Y. Ma, Carbon 52, 254 (2014)

[8] W.M. Tucho, H. Mauroy, J.C. Walmsley, S. Deledda, R. Holmestad, B.C. Hauback, Scr. Mater. 63, 637 (2010)

[9] Z.D. Tao, H.R. Geng, K. Yu, Z.X. Yang, Y.Z. Wang, Mater. Lett. 58, 3410 (2004)

[10] Z.Y. Liu, S.J. Xu, B.L. Xiao, P. Xue, W.G. Wang, Z.Y. Ma, Compos. A 43, 2161 (2012)

[11] L.Y. Chen, H. Konishi, A. Fehrenbacher, C. Ma, J.Q. Xu, H.S. Choi, H.F. Xu, F.E. Pfefferkorn, X.C. Li, Scr. Mater. 67, 29 (2012)

[12] L.Y. Chen, J.Y. Peng, J.Q. Xu, H.S. Choi, X.C. Li, Scr. Mater. 69, 634 (2013)

[13] J. Hashim, L. Looney, M.S.J. Hashmi, J. Mater. Process. Technol. 92-93, 1 (1999)

[14] J.C. Yan, Z.W. Xu, L. Shi, X. Ma, S.Q. Yang, Mater. Des. 32, 343 (2011)

[15] X.J. Wang, X.S. Hu, K. Wu, M.Y. Zheng, L. Zhen, Q.J. Zhai, J. Mater. Sci. 44, 2759 (2009)

[16] S.J. Yoo, S.H. Han, W.J. Kim, Scr. Mater. 68, 711 (2013)

[17] S.R. Bakshi, A. Agarwal, Carbon 49, 33 (2011)

[18] S.Y. Liu, F.P. Gao, Q.Y. Zhang, X. Zhu, W.Z. Li, Trans. Nonferrous Met. Soc. China 20, 1222 (2010)

[19] Z.Y. Liu, B.L. Xiao, W.G. Wang, Z.Y. Ma, Carbon 50, 1843 (2012)

[20] H.J. Choi, G.B. Kwon, G.Y. Lee, D.H. Bae, Scr. Mater. 59, 360 (2008) 